\title{
Nanoemulsions containing a synthetic chalcone as an alternative for treating cutaneous leshmaniasis: optimization using a full factorial design
}

This article was published in the following Dove Press journal:

International Journal of Nanomedicine

I September 2015

Number of times this article has been viewed

\author{
Cristiane Bastos de Mattos' \\ Débora Fretes Argenta' \\ Gabriela de Lima \\ Melchiades' \\ Marlon Norberto Sechini \\ Cordeiro² \\ Maiko Luis Tonini ${ }^{3}$ \\ Milene Hoehr Moraes ${ }^{3}$ \\ Tanara Beatriz Weber ${ }^{4}$ \\ Silvane Souza Roman ${ }^{4}$ \\ Ricardo José Nunes ${ }^{2}$ \\ Helder Ferreira Teixeira' \\ Mário Steindel ${ }^{3}$ \\ Letícia Scherer Koester \\ 'Faculdade de Farmácia, Programa \\ de Pós-Graduação em Ciências \\ Farmacêuticas, Universidade \\ Federal do Rio Grande do Sul, \\ Porto Alegre, Rio Grande do Sul, \\ Brazil; ${ }^{2}$ Departamento de Química, \\ ${ }^{3}$ Departamento de Microbiologia, \\ Imunologia e Parasitologia, \\ Universidade Federal de Santa \\ Catarina, Florianópolis, Santa \\ Catarina, Brazil; ${ }^{4}$ Departamento de \\ Ciências Biológicas, Universidade \\ Regional Integrada do Alto Uruguai e \\ das Missões, Erechim, Rio Grande do \\ Sul, Brazil
}

Correspondence: Letícia Scherer Koester Faculdade de Farmácia, Programa de PósGraduação em Ciências Farmacêuticas, Universidade Federal do Rio Grande do Sul, 2752 Avenida Ipiranga, Porto Alegre, Rio Grande do Sul, 90610-000, Brazil

Email leticia.koester@ufrgs.br

\begin{abstract}
Nanoemulsions are drug delivery systems that may increase the penetration of lipophilic compounds through the skin, enhancing their topical effect. Chalcones are compounds of low water solubility that have been described as promising molecules for the treatment of cutaneous leishmaniasis (CL). In this context, the aim of this work was to optimize the development of a nanoemulsion containing a synthetic chalcone for CL treatment using a $2^{2}$ full factorial design. The formulations were prepared by spontaneous emulsification and the experimental design studied the influence of two independent variables (type of surfactant - soybean lecithin or sorbitan monooleate and type of co-surfactants - polysorbate 20 or polysorbate 80 ) on the physicochemical characteristics of the nanoemulsions, as well as on the skin permeation/ retention of the synthetic chalcone in porcine skin. In order to evaluate the stability of the systems, the antileishmanial assay was performed against Leishmania amazonensis 24 hours and 60 days after the preparation of the nanoemulsions. The formulation composed of soybean lecithin and polysorbate 20 presented suitable physicochemical characteristics (droplet size $171.9 \mathrm{~nm}$; polydispersity index 0.14 ; zeta potential $-39.43 \mathrm{mV}$; $\mathrm{pH} 5.16$; and viscosity $2.00 \mathrm{cP}$ ), drug content $(91.09 \%)$ and the highest retention in dermis $\left(3.03 \mu \mathrm{g} \cdot \mathrm{g}^{-1}\right)$ - the main response of interest - confirmed by confocal microscopy. This formulation also presented better stability of leishmanicidal activity in vitro against $L$. amazonensis amastigote forms (half maximal inhibitory concentration value $0.32 \pm 0.05 \mu \mathrm{M}$ ), which confirmed the potential of the nanoemulsion soybean lecithin and polysorbate 20 for CL treatment.
\end{abstract}

Keywords: leishmaniasis, chalcone, nanoemulsion, full factorial, skin permeation

\section{Introduction}

Cutaneous leishmaniasis (CL) is an infectious disease occurring worldwide known by its ability to produce deformities in the skin. The disease is caused by different species of protozoan parasites that belong to the genus Leishmania. Transmission occurs through the bite of the Phlebotomine sandfly, causing an initial injury in the dermis. ${ }^{1}$ Approximately 1.5 million cases are estimated to occur each year in 82 countries. ${ }^{2}$

The aminoglycoside antibiotic paromomycin has been used as a topical treatment for CL in combination with the cationic surfactant methylbenzethonium chloride, showing good results when compared with placebo. However, paromomycin combined with cationic surfactant mehylbenzethonium chloride was not as effective as the treatment with pentavalent antimony compounds. ${ }^{3}$ An ointment with $15 \%$ paromomycin and $12 \%$ cationic surfactant presented severe skin irritancy, possibly due to the high surfactant concentration. ${ }^{3}$ Formulations containing $10 \%$ urea $^{4}$ or $0.5 \%$ gentamicin ${ }^{5}$ in place of the cationic surfactant were not as effective as vehicle alone against Leishmania major. 
Other topical treatments that showed low or even no cure rates include the use of $1 \%$ clotrimazole cream $\left(\right.$ Canesten ${ }^{\circledR}$ ), $2 \%$ miconazole and ketoconazole cream, ${ }^{6-8} 7.5 \%$ imiquimod cream, ${ }^{9}$ amphotericin B (Fungizone ${ }^{\circledR}$ ) and miltefosine cream. ${ }^{10}$

Therefore, current opinions agree that the topical treatment of CL has not reached optimal effectiveness. ${ }^{11}$ Meanwhile, chalcones and their derivatives have been investigated as potential drug candidates for Leishmaniasis treatment, since their antileishmanial activity has been demonstrated by different authors. ${ }^{12-15}$ A new chalcone derivative, (E)-3(3-nitrophenyl)-1-(3,4,5-trimethoxyphenyl) prop-2-en-1-one (called SC) (Figure 1), was recently synthesized by our research group and showed a promising activity against both promastigotes and intracellular amastigotes of Leishmania amazonensis.

Recently, Rossi-Bergmann et al ${ }^{16}$ investigated the incorporation of synthetic chalcones in the bilayer of small conventional unilamellar liposomes, and demonstrated that disturbances in the bilayer structure result in the formation of deformable liposomes with enhanced epidermal penetration, when compared with pegylated liposomes.

Nanoemulsions are drug delivery systems that have been increasingly investigated as a promising alternative for the treatment of skin diseases, since their small particle sizes can increase the penetration of lipophilic compounds through the skin, enhancing their topical effect. ${ }^{17,18}$ Besides their potential to overcome the epidermal barrier, nanoemulsions present high drug loading, easy preparation/scale-up, and may be composed by biocompatible ingredients, among other advantages. ${ }^{19}$

Since an effective topical treatment for CL may require drug penetration down to the dermis (the layer where the parasite is internalized in macrophages), the incorporation of SC ( $\log$ P 3.7) in the oil core of colloidal carriers such as nanoemulsions seems to be an appealing approach for such purpose.

The aim of this study was to perform a $2^{2}$ full factorial design in order to investigate the effect of different surfactants and co-surfactants on the physicochemical characteristics of

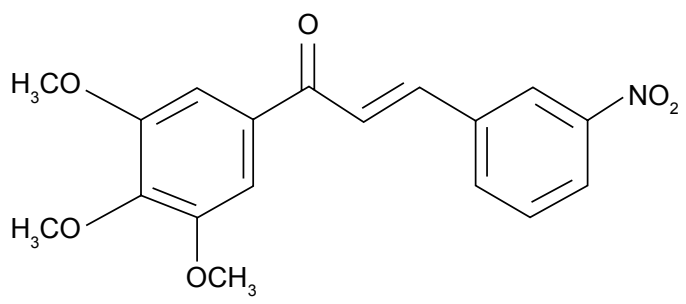

Figure I Structure of (E)-3-(3-nitrophenyl)-I-(3,4,5-trimethoxyphenyl) prop-2-enI-one. nanoemulsions containing SC, as well as on the SC skin permeation/retention in the different skin layers of porcine ear. Subsequently, we compared the in vitro leishmanicidal activity of the selected SC-loaded nanoemulsion against L. amazonensis amastigotes with SC alone.

\section{Experimental}

\section{Chemical and reagents}

SC (purity of $97.8 \%$ ) was synthesized and supplied by The Structure-Activity Laboratory on Department of Chemistry of Federal University of Santa Catarina, Brazil. Soy lecithin (Lipoid S-75 ${ }^{\circledR}$ ) and medium chain triglycerides (MCT) were kindly given by Lipoid GmbH (Ludwigshafen, Germany). Polysorbates 80 and 20 (Tween $80^{\circledR}$ and Tween $20^{\circledR}$, respectively), sorbitan monooleate (Span $80^{\circledR}$ ), and Nile red were purchased from Sigma Chemical Company (St Louis, MO, USA). Trifluoroacetic acid was purchased from Merck (Deisenhofen, Germany). Ultrapure water was obtained from a Milli-Q ${ }^{\circledR}$ Plus apparatus by Millipore (Merck Millipore, Billerica, MA, USA). Methanol liquid chromatography (LC) grade was obtained from Tedia (Rio de Janeiro, Brazil). All other reagents were of analytical grade.

\section{Chromatographic conditions and apparatus}

The LC apparatus consisted of a Shimadzu LC-10A system (Kyoto, Japan) equipped with a model LC-20AT pump, a SPD-20AV UV-VIS variable wavelength detector, a DGU20A5 degasser, a CBM-20A system controller, and SIL-20A injection valve with a $100 \mu \mathrm{L}$ loop. The chalcone was analyzed using a Phenomenex Luna RP18 column (150 mm $\times$ $4 \mathrm{~mm}, 5 \mu \mathrm{m}$ particle size) coupled to a RP18 guard column. The mobile phase consisted of methanol:trifluoroacetic acid $(0.1 \%)(70: 30 \mathrm{v} / \mathrm{v})$. The injection volume was $20 \mu \mathrm{L}$ and the $\mathrm{LC}$ system was operated at an isocratic flow of $1.0 \mathrm{~mL} \cdot \mathrm{min}^{-1}$, with detection at $288 \mathrm{~nm}$, and temperature at $30^{\circ} \mathrm{C}$.

\section{Factorial design}

A $2^{2}$ full factorial design was used to determine the influence of two factors: type of lipophilic surfactant (A) and type of hydrophilic surfactant (co-surfactant) (B) and interactions between them on the following responses: droplet size, polydispersion index, zeta potential, $\mathrm{pH}$, viscosity, drug content and association, and drug retention in skin layers. The factorial design matrix is shown in Table 1. Results were demonstrated as Pareto charts that identify which factors and interactions between them have a significant influence on each response assessed. In interaction graphs, the greater slope of the line indicates the larger influence 
Table I Nanoemulsion composition (\%, w/w) and matrix factorial design

\begin{tabular}{lllll}
\hline Compounds & LP20 & SP80 & LP80 & SP20 \\
\hline Chalcone & 0.1 & 0.1 & 0.1 & 0.1 \\
MCT & 10.0 & 10.0 & 10.0 & 10.0 \\
Sorbitan monooleate & - & $2.0^{(-1)}$ & - & $2.0^{(-1)}$ \\
Soybean lecithin & $2.0^{(+1)}$ & - & $2.0^{(+1)}$ & - \\
Polysorbate 20 & $2.0^{(+1)}$ & - & - & $2.0^{(+1)}$ \\
Polysorbate 80 & - & $2.0^{(-1)}$ & $2.0^{(-1)}$ & - \\
Water qsP & 100.0 & 100.0 & 100.0 & 100.0 \\
\hline
\end{tabular}

Notes: Factor A: lipophilic surfactant. High level $(+1)$ : soybean lecithin. Low level $(-1)$ : sorbitan monooleate. Factor B: hydrophilic surfactant. High level (+I): polysorbate 20. Low level $(-1)$ : polysorbate 80. "-" Indicates absence of this compound.

Abbreviations: LP20, soybean lecithin and polysorbate 20; LP80, soybean lecithin and polysorbate 80 ; $\mathrm{MCT}$, medium chain triglycerides; qsp, a sufficient quantity for; SP20, sorbitan monooleate and polysorbate 20; SP80, sorbitan monooleate and polysorbate 80 .

of the variables on the system, and the lack of parallelism of lines indicates the interaction between the factors. Statistical significance of each individual factor and interactions between factors and effects were determined at $5 \%$ significance level by using the Minitab software (Minitab 14, Statistical Software).

\section{Nanoemulsions preparation}

Nanoemulsions were prepared using a spontaneous emulsification procedure. ${ }^{20}$ All formulations contain MCT as oily core, and were named according to the mixture of lipophilic (factor A) and hydrophilic (factor B) surfactants employed: soybean lecithin and polysorbate 20 (LP20), soybean lecithin and polysorbate 80 (LP80), sorbitan monooleate and polysorbate 20 (SP20), and sorbitan monooleate and polysorbate 80 (SP80). SC was incorporated at $1.0 \mathrm{mg} \cdot \mathrm{mL}^{-1}$ in all nanoemulsions (Table 1). Blank nanoemulsions were prepared without the incorporation of SC.

\section{Physicochemical characterization}

Particle size and zeta potential were measured at $25^{\circ} \mathrm{C}$ by photon correlation spectroscopy and electrophoretic mobility, respectively, using a Malvern Zetasizer ${ }^{\circledR}$ Nano-ZS 90 (Malvern Instruments, Malvern, UK). For droplet size and zeta potential analysis, before the measurement samples were diluted 1:1,000 with ultrapure water and $1.0 \mathrm{mM} \mathrm{NaCl}$ solution, respectively. Viscosity was determined by capillary viscometry in an Ostwald viscometer. Tests were performed taking into account the flow time of samples (adjusted to $20^{\circ} \mathrm{C} \pm 0.1^{\circ} \mathrm{C}$ ) through the capillary. $\mathrm{pH}$ was determined using a Digimed potentiometer (São Paulo, Brazil). All analyses were done in triplicate.

\section{Morphological analysis}

Morphological analysis of nanoemulsions was performed by transmission electron microscopy (TEM). A nanoemulsion drop was placed on a copper grid (200 mesh) coated with Formvar/carbon. After 1 minute, the sample was removed by capillarity with a piece of paper. A drop of $1 \%$ uranil acetate was added and, after 2 minutes, its liquid was removed by capillarity. The samples were analyzed using a JEM-1200 EXII instrument (JEOL, Tokyo, Japan).

\section{SC content and association efficiency}

The SC content in the nanoemulsions was assayed by LC after sample dilution in methanol. In order to determine the association efficiency, the nanoemulsion ultrafiltrationcentrifugation was performed using Ultrafree ${ }^{\circledR}$ MC 10,000 MW (Millipore) membrane for 10 minutes at 15,000 rpm. The amount of SC associated with the nanoemulsions was calculated as the difference between the total and free SC concentrations determined in the nanoemulsion and ultrafiltrate, respectively.

\section{In vitro skin permeation/retention}

The skin permeation/retention study was performed in a Franz-type diffusion cell with a nominal area of $1.77 \mathrm{~cm}^{2}$ and receptor cell volume of $10 \mathrm{~mL}$. Porcine ear skin was used as membrane between donor and receptor compartment. The subcutaneous lipid tissue was removed and the skin was stored in a freezer for up to 1 month. The nanoemulsion $(0.5 \mathrm{~mL})$ was placed in the donor compartment and phosphate buffer (pH 7.4): ethanol (50:50, v/v) was employed as receptor fluid, in the receptor compartment. The control formulation was composed by a suspension of SC in MCT $\left(1.0 \mathrm{mg} \cdot \mathrm{mL}^{-1}\right)$. The temperature of the receptor fluid was maintained at $32^{\circ} \mathrm{C} \pm 1^{\circ} \mathrm{C}$ under constant stirring. After 8 hours, the skin was removed from the cell and cleaned using cotton swab. Tape stripping experiments were performed on full-thickness porcine ear skin using Scotch Tape 750 (3M, St Paul, MN, USA). The first stripped tape was discarded, while the following 14 tapes were submitted to SC extraction. After, the epidermis was separated from the dermis using a scalpel and the layers were weighed. SC was extracted from tapes, epidermis, or dermis in $2 \mathrm{~mL}$ of methanol in ultrasound bath for 30 minutes. Samples were filtered through $0.45 \mu \mathrm{m}$ Millipore membranes and analyzed by high-performance LC at $288 \mathrm{~nm}$ as previously described. The results were expressed as mean \pm standard deviation $(n=6)$ of SC per skin weight $\left(\mu \mathrm{g} \cdot \mathrm{g}^{-1}\right)$.

\section{Histological analysis}

Histological analyses were performed in order to observe skin morphology changes after treatment with different 
nanoemulsions, for 8 hours, on a Franz diffusion cell. Skin was cleaned with a swab and immersed in formaldehyde solution. Subsequently, the skin was dehydrated, paraffin embedded, sectioned and colored by hematoxylin-eosin. Skin tissues were observed under optical microscopy using tenfold magnification.

\section{Confocal fluorescence microscopy}

Confocal fluorescence microscopy was used to visualize the distribution of fluorescent nanoemulsions through the skin layers. Nile red was added $(0.05 \%)$ to the organic phase during nanoemulsion preparation. After 8 hours of application in the Franz diffusion cell, the skin samples were mounted with Tissue-tec O.C.T. ${ }^{\circledR}$ (Sakura Finetechnical, Tokyo, Japan) onto a metal sample holder and frozen at $-20^{\circ} \mathrm{C}$. Vertical $40 \mu \mathrm{m}$ thick slices were obtained with a cryostat (Leica CM 1850) and the slides were evaluated using a confocal microscopic Olympus FluoView ${ }^{\mathrm{TM}} 1000$. The excitation and emission wavelengths were $559 \mathrm{~nm}$ and $636 \mathrm{~nm}$, respectively. The images were taken at a 20 -fold optical zoom.

\section{Parasites}

L. amazonensis (Clone C12D9) genetically modified to express the $\beta$-galactosidase enzyme ${ }^{21}$ were maintained as promastigotes at $26^{\circ} \mathrm{C}$ in Schneider's insect medium (SigmaAldrich, St Louis, MO, USA), pH 7.4, supplemented with $10 \%(\mathrm{v} / \mathrm{v})$ heat inactivated fetal bovine serum (Gibco, BRL), $2 \%(\mathrm{v} / \mathrm{v})$ human urine, $10 \mathrm{U} \cdot \mathrm{mL}^{-1}$ penicillin, $10 \mu \mathrm{g} \cdot \mathrm{mL}^{-1}$ streptomycin (Gibco, BRL) and $500 \mu \mathrm{g} \cdot \mathrm{mL}^{-1} \mathrm{G}-418$ (Santa Cruz Biotechnology, Dallas, TX, USA). The THP-1 cell line of acute human monocytic leukemia ${ }^{22}$ was maintained at $37^{\circ} \mathrm{C}$ and $5 \% \mathrm{CO}_{2}$ in RPMI 1,640 medium without phenol red (Sigma-Aldrich), pH 7.4 supplemented with $10 \%$ $(\mathrm{v} / \mathrm{v})$ heat inactivated fetal bovine serum, $12.5 \mathrm{mM}$ HEPES buffer (Gibco, BRL), $100 \mathrm{U} \mathrm{mL}^{-1}$ penicillin, $100 \mu \mathrm{g} \cdot \mathrm{mL}^{-1}$ streptomycin (Gibco, BRL), 2 mM Glutamax ${ }^{\circledR}$ (Gibco, BRL), and $1 \mathrm{mM}$ sodium pyruvate (Gibco, BRL). This study was approved by the UFSC Ethics Committee (Universidade Federal de Santa Catarina, Florianópolis, Santa Catarina, Brazil) under protocol (UFSC- 332109/2013).

\section{Antiparasitic assay}

The antiparasitic assay was performed according to Tonini ${ }^{21}$ and Fumarola et al. ${ }^{23}$ Briefly, differentiation of THP-1 cells into adherent macrophage-like cells was achieved by treatment with phorbol myristate acetate in 96-well plates for 72 hours. Adherent cells were infected with L. amazonensis (C12D9) promastigotes (multiplicity of infection of 10) for
3 hours and incubated for another 24 hours. Subsequently, cells were treated with SC or nanoemulsions at concentrations of $0.375,0.75,1.25,2.5,5.0,10.0$, and $20.0 \mu \mathrm{g} \cdot \mathrm{mL}^{-1}$ and cultivated for 48 hours at $34^{\circ} \mathrm{C}$ and $5 \% \mathrm{CO}_{2}$. The supernatant was removed, and a solution containing $250 \mu \mathrm{L}$ PBS $+\mathrm{CPRG}$ $(100 \mathrm{mM})+0.1 \% \mathrm{NP}-40(\mathrm{v} / \mathrm{v})$ was added and developed for 16 hours at $37^{\circ} \mathrm{C}$, when the optical density was measured in a spectrophotometer at $570 \mathrm{~nm}$ Tecan $^{\circledR}$ Model Infinite M200. Amphotericin B and DMSO were used as positive and negative controls, respectively. In order to evaluate the nanoemulsion inhibition profile against amastigotes of L. amazonensis, the concentrations used were $0.375,0.75$, $1.25,2.5,5.0,10.0$, and $20.0 \mu \mathrm{g} \cdot \mathrm{mL}^{-1}$. Half maximal inhibitory concentration $\left(\mathrm{IC}_{50}\right)$ values were calculated by a non-linear regression model using GraphPad Prism 5.03 ${ }^{\circledR}$ (GraphPad Software Inc, San Diego, CA, USA).

\section{Cytotoxicity assay}

Cell viability was determined by the 3-(4,5-dimethylthiazol2-yl)-2,5-diphenyltetrazolium bromide (MTT) method as described by van de Loosdrecht et $\mathrm{al}^{24}$ and modified by Sieuwerts et al. ${ }^{25}$ THP- 1 cells were seeded in 96 -well plates $\left(4 \times 10^{4}\right.$ cells/well) in $180 \mu \mathrm{L}$ of complete RPMI medium. Compounds diluted in the culture medium at decreasing concentrations from 250 to $7.81 \mu \mathrm{M}$ were added to the cells, which were then grown for 48 hours at $37^{\circ} \mathrm{C}$ and $5 \% \mathrm{CO}_{2}$. Later, the plates were centrifuged $(2,700 \times g / 10$ minutes $)$, the supernatant was removed, and the pellet was resuspended in $50 \mu \mathrm{L}$ of a solution of MTT (Sigma-Aldrich) at $3 \mathrm{mg} \cdot \mathrm{mL}^{-1}$ as described by Garcia et al. ${ }^{26}$ Subsequently, the plates were incubated at $37^{\circ} \mathrm{C}$ in the absence of light for 4 hours and centrifuged $(2,700 \times$ $g / 10$ minutes). The supernatant was removed and the pellet (formazan salt) solubilized in $100 \mu \mathrm{L}$ DMSO. Optical density was determined at $540 \mathrm{~nm}$ in a Tecan ${ }^{\circledR}$ Infinite M200 spectrophotometer. DMSO 1\% (v/v) and DMSO 20\% (v/v) were the negative and positive controls, respectively. Amphotericin $\mathrm{B}$ has been tested at concentrations of up to $10 \mu \mathrm{M}$. Fifty percent cytotoxic concentration values were calculated by a non-linear regression using the GraphPad Prism $5.03{ }^{\circledR}$ program.

\section{Statistical analysis}

One-way analysis of variance with Tukey's post-test was used to evaluate differences between mean values. Differences were considered as statistically significant when $P<0.05$.

\section{Results and discussion}

Non-ionic (sorbitan monooleate) and amphoteric (soybean lecithin) surfactants were selected for the nanoemulsion 
optimization study, since they are widely used in the preparation of nanostructured systems due to their low toxicity. ${ }^{27-29}$ In addition, lecithin has high affinity for cell membranes, affording increased drug absorption, which is ideal for the development of nanoemulsions.

Co-surfactants can be employed to stabilize the interface by steric hindrance, thereby forming more stable emulsions. For this purpose, the non-ionic surfactants, such as polysorbates, are the most widely used..$^{30}$ Recent studies showed that surfactants with similar HLB provided the formation of nanoemulsions with different characteristics, such as droplet size, surface tension, and mobility. These studies also revealed that, other surfactant properties, like molecular geometry, for instance, are important to determine the effectiveness of these compounds in the formation of nanoemulsions, using low energy methods, such as spontaneous emulsification. ${ }^{31}$ Polysorbates 20 and 80 present similar HLB values (16.7 and 15.0, respectively). Both have similar groups in the polar head and non-polar tails. Polysorbate 20 has a linear saturated chain, whereas the polysorbate 80 chain is unsaturated and more kinked. The difference in geometry may affect the link between the oil-water interface and the surfactant, and the presence of double bonds in the non-polar tails is thought to promote the formation of smaller droplet sizes. ${ }^{32}$ Polysorbates 20 and 80 were selected to investigate whether surfactants with similar HLB may form nanoemulsions with different physicochemical characteristics and skin permeation capacity.

The oil core was selected based on solubility studies of SC, which showed a higher solubility in MCT $\left(2.8 \pm 0.05 \mathrm{mg} \cdot \mathrm{g}^{-1}\right)$ compared with castor oil $\left(2.0 \pm 0.13 \mathrm{mg} \cdot \mathrm{g}^{-1}\right)$, MCT: castor oil mixture $\left(2.3 \pm 0.40 \mathrm{mg} \cdot \mathrm{g}^{-1}\right)$, vitamin E $\left(1.4 \pm 1.97 \mathrm{mg} \cdot \mathrm{g}^{-1}\right)$, isopropyl myristate $\left(1.07 \pm 1.25 \mathrm{mg} \cdot \mathrm{g}^{-1}\right)$, and octyldodecanol $\left(0.98 \pm 0.16 \mathrm{mg} \cdot \mathrm{g}^{-1}\right)$.

Table 2 shows the results of the physicochemical characteristics of the nanoemulsions developed. All formulations presented high content and encapsulation efficiency, indicating that the spontaneous emulsification was a suitable method for nanoemulsion preparation. Another important parameter is particle size, which defines whether the formulations are in the nanometric range and may affect the penetration of the active substance through the skin. ${ }^{33}$ Nanoemulsions containing soybean lecithin showed a droplet size ranging from 171.9 to $183.7 \mathrm{~nm}$, while those composed by sorbitan monooleate ranged from 272.4 to $296.2 \mathrm{~nm}$. The polydispersity index (PDI) reflects the distribution of particle size in a formulation. A PDI of $<0.2$ indicates the existence of uniform size distribution and homogenous populations, whereas a PDI of $>0.3$ indicates system heterogeneity. ${ }^{34}$ Nanoemulsions prepared with soybean lecithin presented PDI values between 0.13 and 0.14 , while those prepared with sorbitan monooleate ranged within 0.24 and 0.34 .

The negative zeta potential values displayed by nanoemulsions containing sorbitan monooleate $(-21.22$ to $-25.8 \mathrm{mV})$ may be credited to the presence of free fatty acids from MCT, to the adsorption of hydroxyl ions at the oil in water interface, and to the subsequent development of hydrogen bonds between these ions and ethylene oxide groups of Tween, as observed by Liu et al. ${ }^{35}$

The presence of soybean lecithin results in a higher value of zeta potential ( -36.61 to $-39.43 \mathrm{mV}$ ), as expected, and this can be attributed to the presence of negatively charged phospholipids. ${ }^{27,30}$ Lecithins are composed by phosphatidylcholine and acid lipids, and at neutral $\mathrm{pH}$ provide a higher negative zeta potential $(-50 \mathrm{mV})$. However, the zeta potential of phospholipid-stabilized nanoemulsions can be reduced in acid $\mathrm{pH}$ values, confirming our results. ${ }^{30,35,36}$ High module zeta potential increases the distance and electrical repulsion between the particles. However, lower zeta potential, as found in nanoemulsions prepared with sorbitan monooleate, does not necessarily reflect system instability. ${ }^{27}$

Nanoemulsion viscosity depends on the nature and concentration of surfactant, oil phase constituents, droplet size,

Table 2 Physicochemical characteristics of nanoemulsions

\begin{tabular}{lllll}
\hline Parameters analyzed & LP20 & SP80 & LP80 & SP20 \\
\hline Content, $\mathrm{mg} \cdot \mathrm{mL}^{-1}(\mathrm{SD})$ & $0.91(0.18)^{\mathrm{a}}$ & $0.89(0.28)^{\mathrm{a}}$ & $0.92(0.60)^{\mathrm{a}}$ & $0.88(0.10)^{\mathrm{a}}$ \\
Association efficiency (SD) & $99.93(0.005)^{\mathrm{a}}$ & $99.97(0.04)^{\mathrm{a}}$ & $99.97(0.02)^{\mathrm{a}}$ & $99.97(0.03)^{\mathrm{a}}$ \\
Particle size, $\mathrm{nm}(\mathrm{SD})$ & $171.9(18.73)^{\mathrm{a}}$ & $272.74(8.85)^{\mathrm{b}}$ & $183.77(1.94)^{\mathrm{a}}$ & $296.27(2.81)^{\mathrm{b}}$ \\
Polydispersity index (SD) & $0.14(0.01)^{\mathrm{a}}$ & $0.24(0.04)^{\mathrm{b}}$ & $0.13(0.02)^{\mathrm{a}}$ & $0.34(0.07)^{\mathrm{b}}$ \\
Zeta potential, mV (SD) & $-39.43(3.56)^{\mathrm{a}}$ & $-21.22(4.59)^{\mathrm{b}}$ & $-36.61(0.58)^{\mathrm{a}}$ & $-25.8(2.68)^{\mathrm{b}}$ \\
PH (SD) & $5.16(0.40)^{\mathrm{a}}$ & $5.81(0.56)^{\mathrm{a}}$ & $5.47(0.31)^{\mathrm{a}}$ & $5.68(0.68)^{\mathrm{a}}$ \\
Viscosity, cP (SD) & $2.00(0.13)^{\mathrm{a}}$ & $1.71(0.06)^{\mathrm{b}}$ & $2.01(0.07)^{\mathrm{a}}$ & $1.75(0.19)^{\mathrm{b}}$ \\
\hline
\end{tabular}

Note: Different letters indicate significant statistical differences (ANOVA, Tukey test, $P<0.05$ ).

Abbreviations: ANOVA, analysis of variance; LP20, soybean lecithin and polysorbate 20; LP80, soybean lecithin and polysorbate 80; SD, standard deviation; SP20, sorbitan monooleate and polysorbate 20; SP80, sorbitan monooleate and polysorbate 80. 
and the viscosity of the oil-forming core. ${ }^{37,38}$ All formulations presented low viscosity, ranging from 1.71 to $2.01 \mathrm{cP}$, which are characteristic of nanoparticulate systems. The nanoemulsions containing soybean lecithin exhibited significantly higher viscosity values, compared with those prepared with monooleate sorbitan as a surfactant, indicating the influence of the lipophilic surfactant. Increased viscosity can also be attributed to the reduced droplet size of nanoemulsions, as observed by $\mathrm{Pal},{ }^{39}$ since the lower the droplet size, the higher the surface area, which increases interparticulate interactions. The $\mathrm{pH}$ of the formulations ranged between 5.16 and 5.81, which are suitable values for cutaneous application and do not interfere in the permeation characteristics of lipophilic molecules. ${ }^{40}$

Physicochemical parameters of blank nanoemulsions were also evaluated (data not shown). The results showed no significant differences when compared with the SC-loaded nanoemulsion.
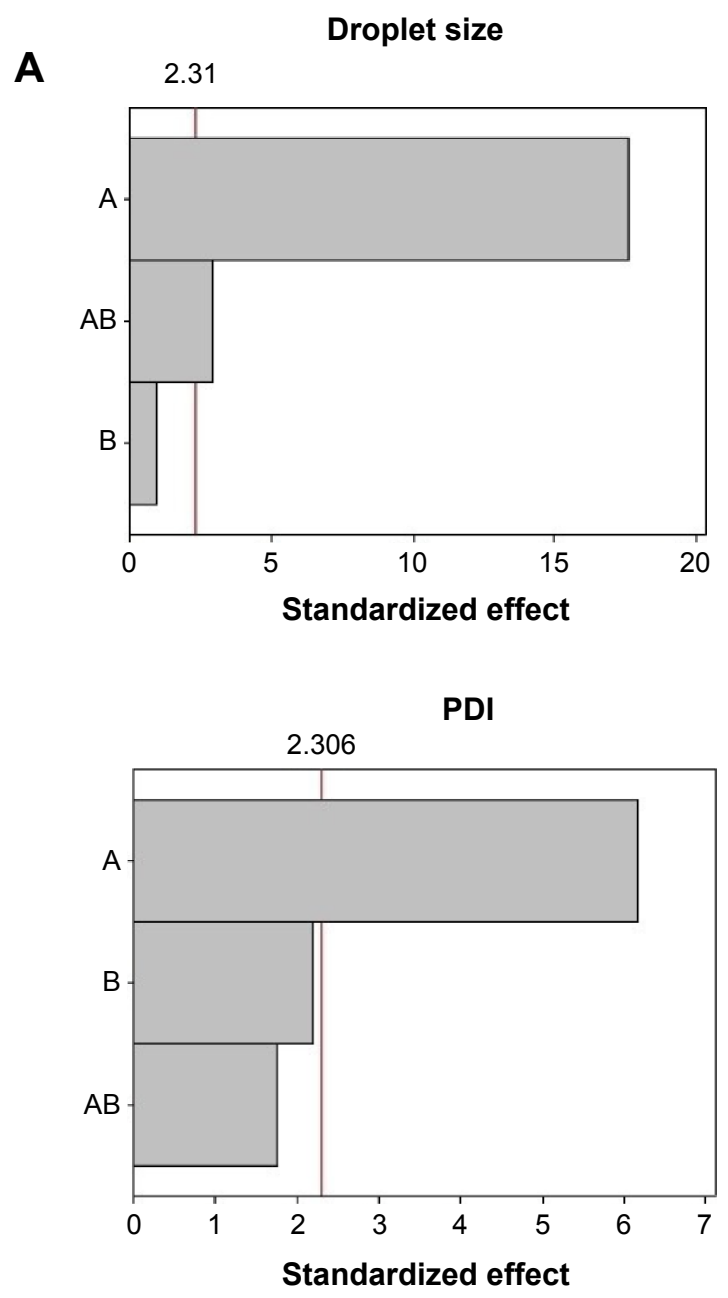

The Pareto chart (a) and interaction graphs (b) are shown in Figure 2. The variable A (lipophilic surfactant) presents a significant influence $(P<0.05)$ on droplet size, PDI, zeta potential, viscosity, and $\mathrm{pH}$, with a favorable effect on all parameters. This effect was observed when the lipophilic surfactant was present at its high level (soybean lecithin), resulting in nanoemulsions with smaller particle size, low PDI, higher zeta potential in module, and viscosity. The interactions between factors A and B present a significant influence only on droplet size. As can be observed in the interaction graphs, droplet sizes are reduced when both factors are at high level, that is, when soybean lecithin and polysorbate 20 are employed in the same formulation. The variable B (hydrophilic surfactant) did not influence nanoemulsions characteristics significantly. These findings suggest that the molecular geometry of the surfactants did not affect the properties of nanoemulsions, contrarily to what has been described in previous studies. ${ }^{31}$

B
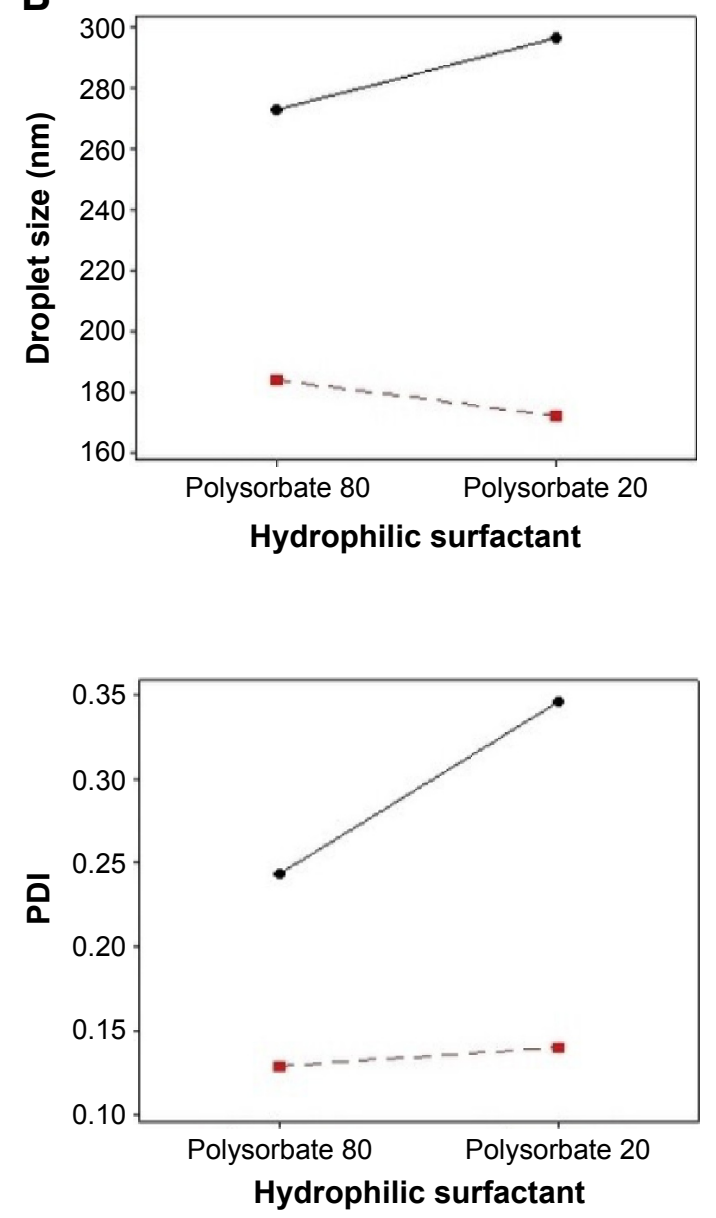

Figure 2 (Continued) 


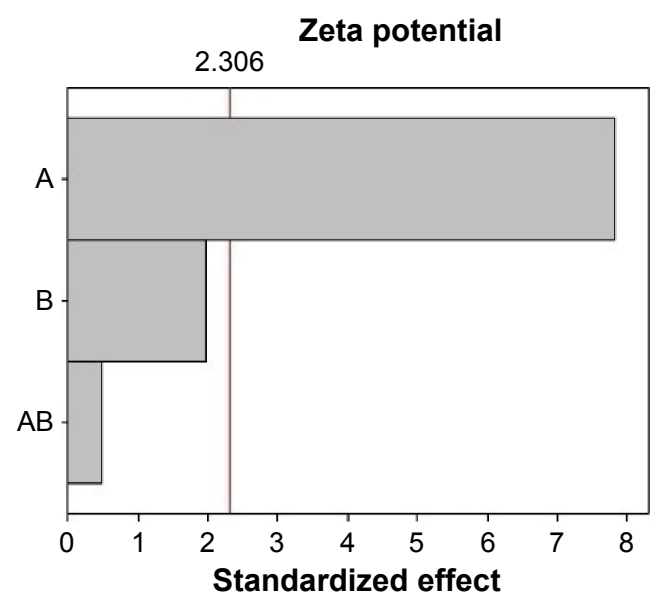

Viscosity
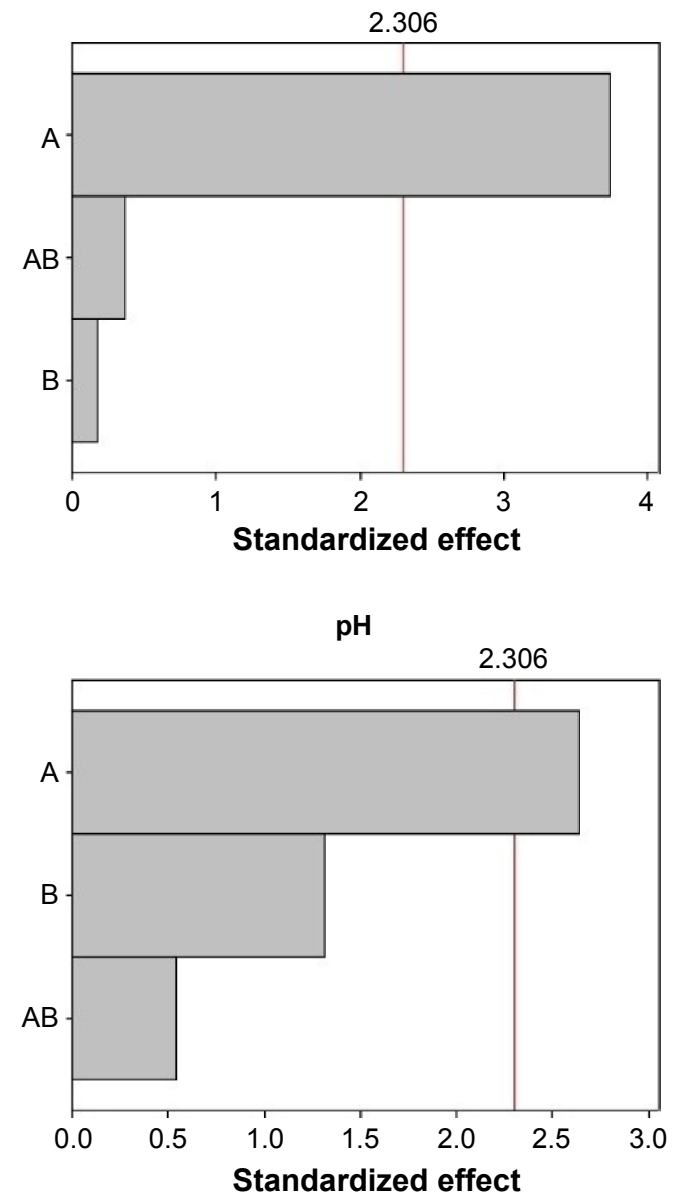
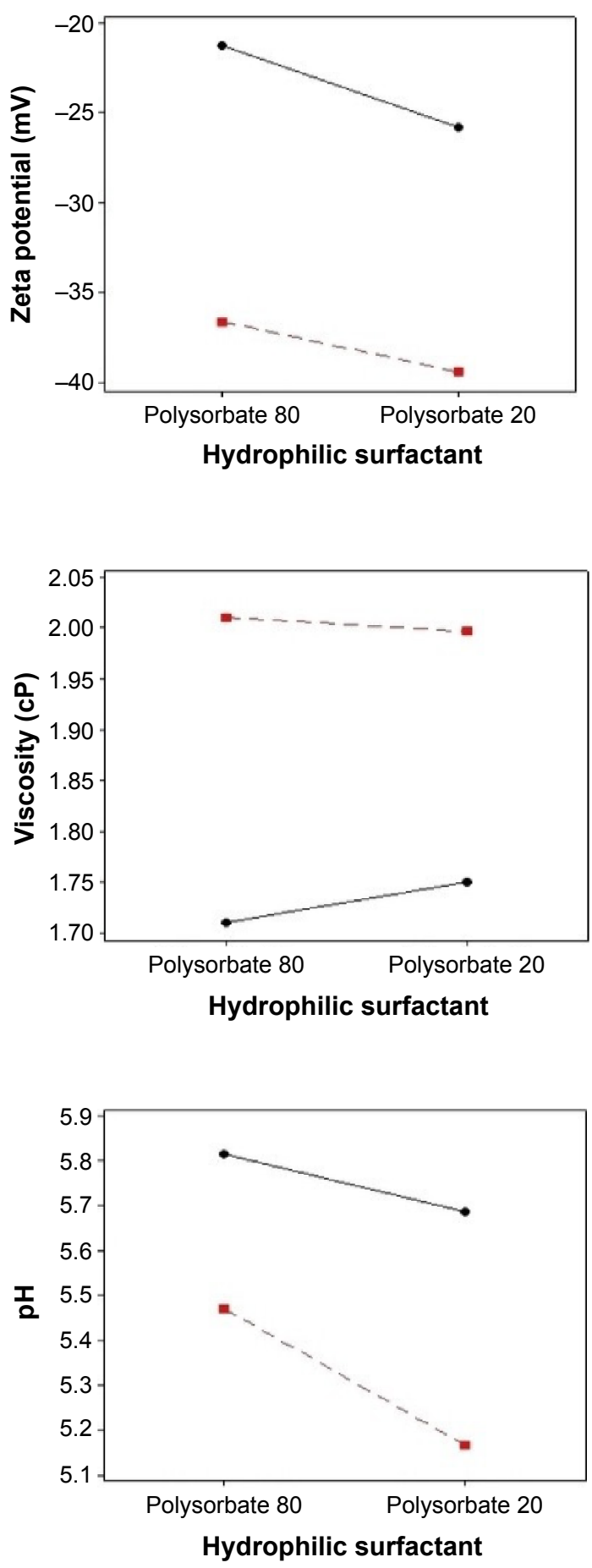

Figure 2 Pareto chart (A) and interaction graphs $(\mathbf{B})$ to physicochemical characteristics.

Notes: A: lipophilic surfactant; B: hydrophilic surfactant. Continuous line: sorbitan monooleate (-I); dotted line: soybean lecithin (+I).

Abbreviation: PDI, polydispersity index.

The Pareto chart for content and association efficiency is presented in Figure 3. As can be observed, neither the variables nor their interactions were significant to these responses.

Morphological analysis were performed based on TEM images (Figure 4) and show that nanoemulsion droplets are almost spherical, presenting the typical appearance of oil in water nanoemulsion, although those prepared with soybean lecithin as a surfactant seem to be more deformable (Figure 4A and B) than those prepared with sorbitan monooleate (Figure 4C and D). The photomicrographs confirm the particle size analysis, which showed droplets in the nanometer range. 
A

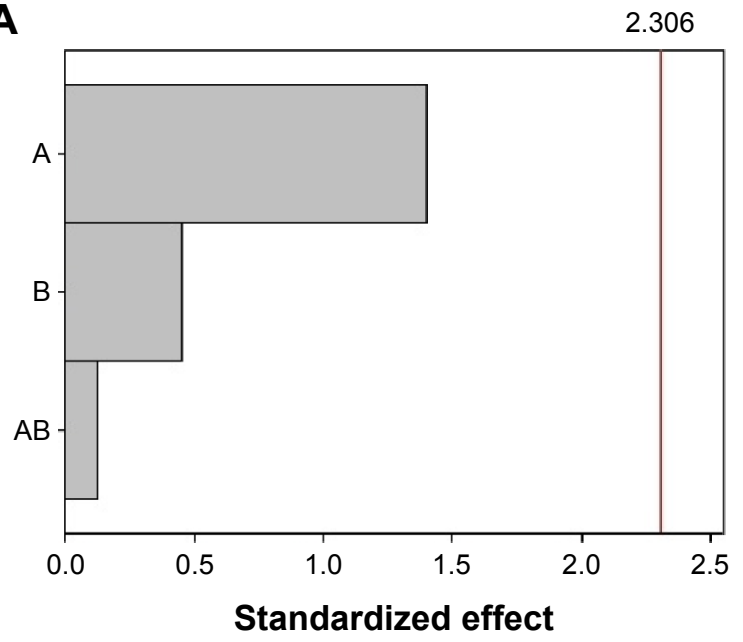

B

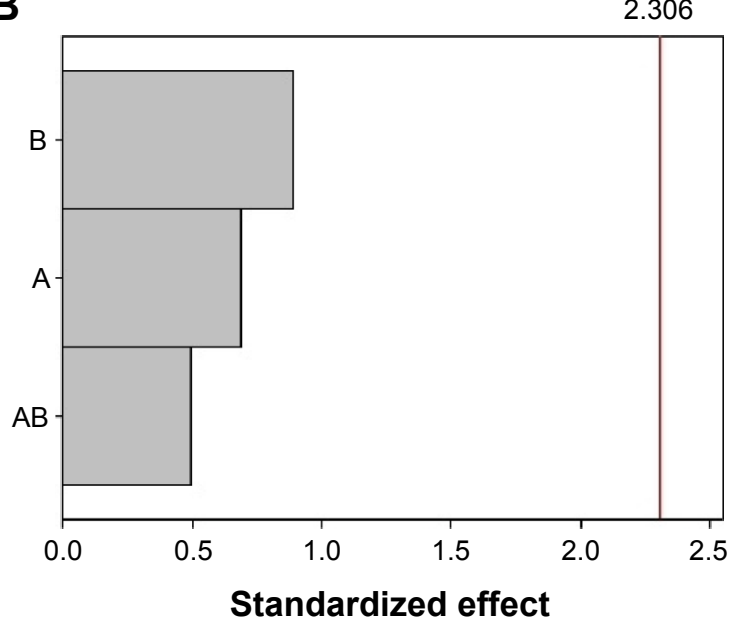

Figure 3 Pareto chart to $(\mathbf{A})$ content and $(\mathbf{B})$ association efficiency. Notes: A: lipophilic surfactant; B: hydrophilic surfactant.
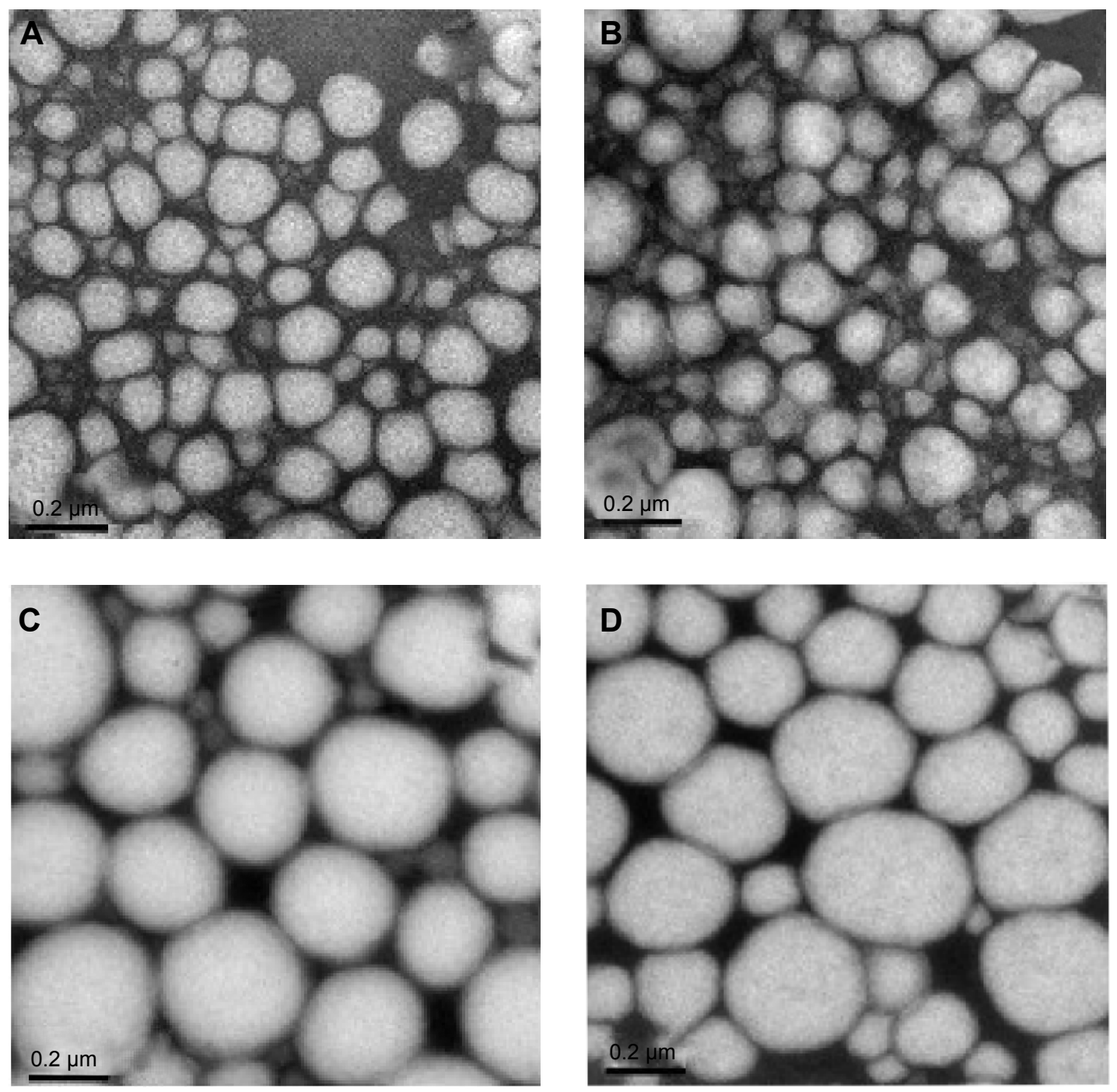

Figure 4 Transmission electronic microscopy images of the nanoemulsions $\times 100,000$ magnification.

Notes: (A) LP20, (B) LP80, (C) SP80, and (D) SP20 (scale bars $0.2 \mu \mathrm{m}$ ).

Abbreviations: LP20, soybean lecithin and polysorbate 20; LP80, soybean lecithin and polysorbate 80 ; SP20, sorbitan monooleate and polysorbate 20; SP80, sorbitan monooleate and polysorbate 80 . 
Particle size, electrical charge, and nature of the surfactants used are factors that influence the interaction between nanoemulsions and skin, and, therefore drug penetration profile. ${ }^{41}$ Some compounds are capable of increasing bilayer fluidity and the diffusion of lipophilic compounds, since they are able to fuse with stratum corneum lipids, thereby inserting themselves between the hydrophobic tails of the bilayer. ${ }^{42}$ Among these compounds, phospholipids can increase tissue hydration due to their physicochemical properties, promoting drug delivery. ${ }^{43}$ The results of the in vitro skin permeation/ retention study are shown in Table 3. After 8 hours of experiment in a Franz-type diffusion cell, SC retention in the epidermis was higher than that in the dermis. SC retention was below lower limit of quantification in stratum corneum, and was not detected in the receptor fluid from all formulations. The amount of SC retained in skin layers from the control formulation was below lower limit of quantification, suggesting its reduced penetration in the free form. SC retention from SP20 formulation was statistically different $(P<0.05)$, compared with the other formulations.

The Pareto chart (Figure 5A) shows that, for SC epidermis retention, variable A (lipophilic surfactant) presented a significant effect, while variable B did not. For dermis retention, both variables presented a significant effect. The $\mathrm{AB}$ interaction had a significant influence on SC epidermis and dermis retention. The interaction graphs (Figure 5B) show that the interaction between $\mathrm{A}$ and $\mathrm{B}$ increased $\mathrm{SC}$ retention in the epidermis when these factors are at low level, and increased SC retention in the dermis layer when these factors are at high level.

Since parasites are located mainly in the dermis, larger SC penetration in this layer is targeted. ${ }^{16,44}$ The results show that, by combining soybean lecithin and polysorbate 20 , a larger $\mathrm{SC}$ retention in the dermis was obtained. This may be attributed to the affinity of lecithin for cellular membranes, and to the ability of polysorbate 20 to form micelles in aqueous medium that extract lipids from the skin. This may lead to an increase in absorption/penetration of several compounds across the skin, allowing these substances to reach deeper layers. ${ }^{45,46}$ Polysorbates can increase drug penetration in the stratum corneum intercellular regions by increasing fluidity and solubilizing lipid components, that is, by providing a looser intracellular lipid barrier in the stratum corneum. ${ }^{47}$ Another possible mechanism suggests the interaction with keratin filaments, which results in corneocytes disruption and drug transport. ${ }^{48,49}$

Akhtar et $\mathrm{al}^{50}$ evaluated the penetration enhancing effect of polysorbates 20 and 80 in the in vitro percutaneous absorption of ascorbic acid. The presence of the non-ionic surfactants increased the influx of ascorbic acid, from 0.626 to 3.17 and $2.44 \mu \mathrm{g} \cdot \mathrm{cm}^{-2} \cdot \mathrm{h}^{-1}$ when polysorbates 20 and 80 were employed, respectively.

In another study, polysorbate 20 produced a significantly higher transdermal flux and permeability coefficient for flurbiprofen compared with polysorbate $80 .{ }^{51}$ The exact mechanism by which polysorbates 20 and 80 seem to produce different results in skin permeation studies has not been clarified up to now.

Figure 6 shows images of histological analysis after 8 hours of skin permeation/retention studies. The histological sections show that nanoemulsions did not modify the structure of untreated skins.

Confocal microscopy shows the skin distribution of fluorescent dyes incorporated in the nanostructures. This technique is non-invasive and provides high-resolution images. ${ }^{52}$ Figure 7 shows images of confocal microscopy after 8 hours of skin permeation/retention studies using a Nile red-SC-loaded nanoemulsion. Higher fluorescence was detected in skins treated with LP20 and SP80, suggesting higher SC retention, compared with other formulations. These images confirm the results of SC epidermal and dermal retention.

In vitro leishmanicidal activity of SC nanoemulsions was evaluated in order to attest the possible potentiation of this activity in these reduced water solubility molecules carrier systems. Our results indicate that the nanoemulsions

Table 3 In vitro chalcone retention $\left(\mu \mathrm{g} \cdot \mathrm{g}^{-1}\right)$ from different nanoemulsions in porcine ear skin after 8 hours (mean \pm SD, $n=6$ )

\begin{tabular}{lllll}
\hline Samples & Receptor fluid & Stratum corneum & Epidermis & Dermis \\
\hline Control & ND & $<$ LLOQ & $<$ LLOQ & $<$ LLOQ \\
LP20 & ND & $<$ LLOQ & $28.19 \pm 6.75^{\mathrm{a}}$ & $3.03 \pm I .18^{\mathrm{a}}$ \\
LP80 & ND & $<$ LLOQ & $20.79 \pm 2.48^{\mathrm{a}}$ & $1.77 \pm 0.34^{\mathrm{a}}$ \\
SP20 & ND & $<$ LLOQ & $13.83 \pm 1.35^{\mathrm{b}}$ & \\
SP80 & ND & $<$ LLOQ & $29.76 \pm 7.33^{\mathrm{a}}$ & $0.56 \pm 0.13^{\mathrm{b}}$ \\
\hline
\end{tabular}

Notes: Different letters indicate significant statistical differences (ANOVA, Tukey test, $P<0.05$ ). $<$ LLOQ: below LLOQ.

Abbreviations: ANOVA, analysis of variance; LLOQ, lower limit of quantification; LP20, soybean lecithin and polysorbate 20; LP80, soybean lecithin and polysorbate 80 ; ND, not detected; SD, standard deviation; SP20, sorbitan monooleate and polysorbate 20; SP80, sorbitan monooleate and polysorbate 80. 

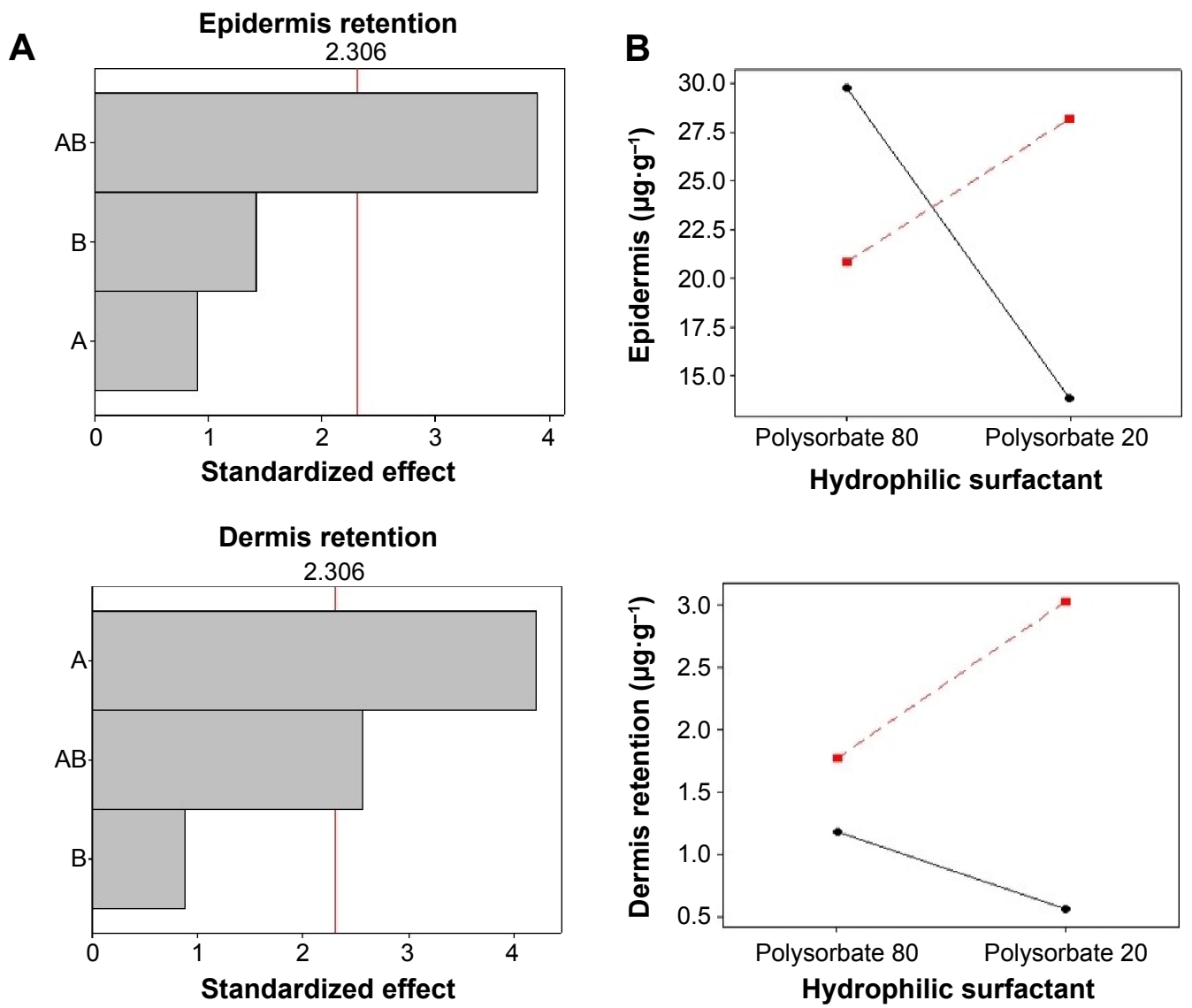

Figure 5 Pareto chart (A) and interaction graphs (B) for SC skin retention.

Notes: A: lipophilic surfactant; B: hydrophilic surfactant. Continuous line: sorbitan monooleate (-I); dotted line: soybean lecithin (+I).

Abbreviation: SC, (E)-3-(3-nitrophenyl)-I-(3,4,5-trimethoxyphenyl) prop-2-en-I-one.

LP20 and SP80 were able to maintain the leishmanicidal activity of this molecule against amastigote forms of $L$. amazonensis (Table 4). Leishmanicidal assays were repeated 60 days after the preparation of the nanoemulsions in order to evaluate the stability of the formulations in which LP20 showed an $\mathrm{IC}_{50}$ of $1.13 \mu \mathrm{g} \cdot \mathrm{mL}^{-1}$, whereas SP80, SP20, and LP80 presented values higher than $20 \mu \mathrm{g} \cdot \mathrm{mL}^{-1}$ (data not shown). The highest percentage of inhibition of parasitic growth was observed after treatment with LP20 in both times stipulated. This formulation showed approximately $100 \%$ of inhibition at most concentrations tested in 24 hours (Figure 8), and presented a slight reduction on its profile after 60 days (data not shown). Cell viability was determined by the MTT technique only for the carrier systems that presented higher antileishmanial activity (ie, LP20 and SP80) (Table 4). Selectivity index (SI) for LP20 and SP80 was 27.97 and 67.42, respectively, which are higher values than the threshold suggested by Grogl et al ${ }^{53}$ as satisfactory for in vitro tests $(>5.0)$. Although LP20 presented lower SI than SP80, this formulation maintained its inhibition profile against L. amazonensis amastigote forms and, therefore, was found to be the best formulation. Furthermore, the drugs used in the current treatment of CL present lower SI values than those found in our results. Glucantime presented SI values of 0.8 and 0.5 , against L. major and Leishmania infantum, respectively. ${ }^{54,55}$ When evaluated against $L$. amazonensis, Glucantime presented SI in range of 0.3-2.4. ${ }^{56}$ The SI of miltefosine was 0.26 against Leishmania donovani ${ }^{57}$ Recent studies investigated the antileishmanial activity of extracts of Hypericum spp., Syzygium cumini essential oil and $\alpha$-pinene against $L$. amazonensis and found SI values ranging from 1.2 to $4.0,10.2$ to 16.1 , and 21.5 to 27.2 , respectively. ${ }^{56,58} \mathrm{~A}$ novel diselenide chitosan hydrogel formulation presented SI of 1.8 against L. major. ${ }^{59}$ Although the positive control presented a good result in this in vitro study, it is worth emphasizing that some cases of Amphotericin B resistance against Leishmania spp. have been recently reported. ${ }^{60,61}$ Taken together, the results of these studies justify the investigation of new drug candidates for Leishmaniasis treatment. 

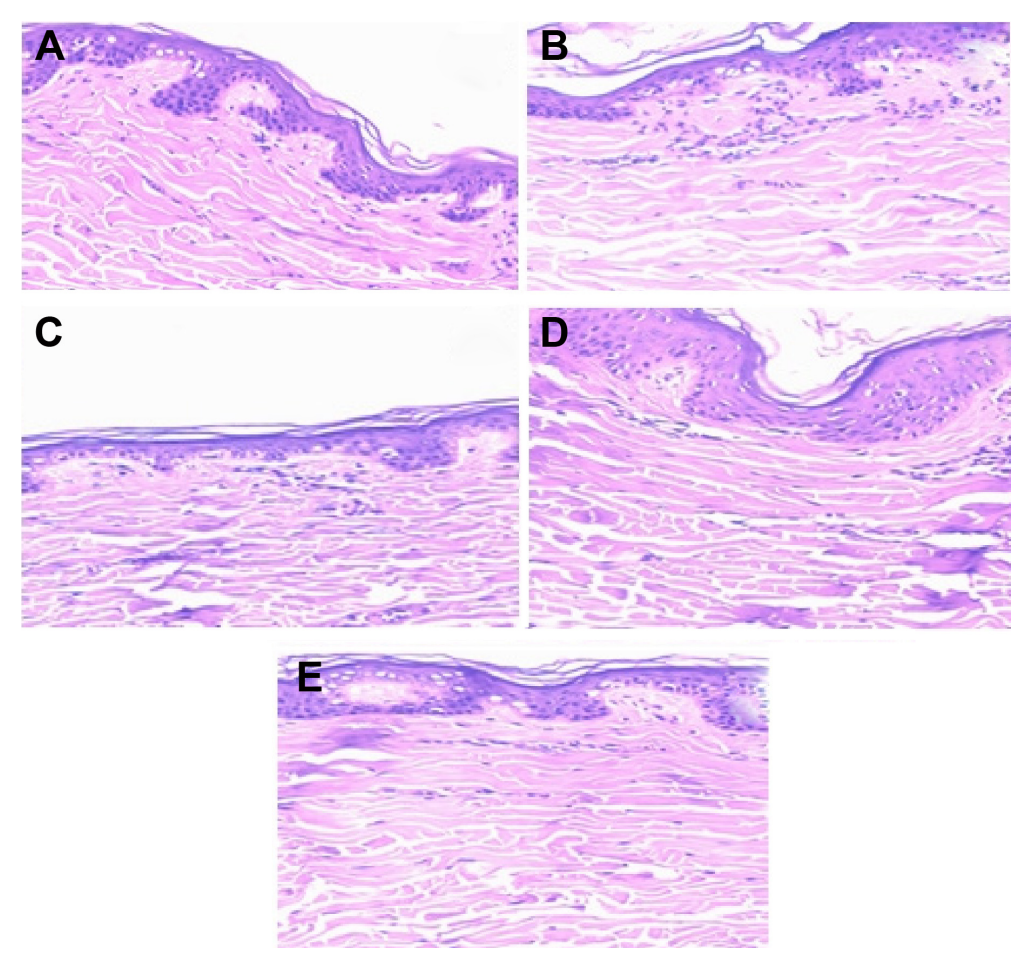

Figure 6 Phytomicrographs of skin after 8 hours of skin permeation (tenfold optical zoom).

Notes: Untreated skin (A); skin treated with LP20 (B), LP80 (C), SP80 (D), and SP20 (E) nanoemulsions.

Abbreviations: LP20, soybean lecithin and polysorbate 20; LP80, soybean lecithin and polysorbate 80; SP20, sorbitan monooleate and polysorbate 20; SP80, sorbitan monooleate and polysorbate 80 .
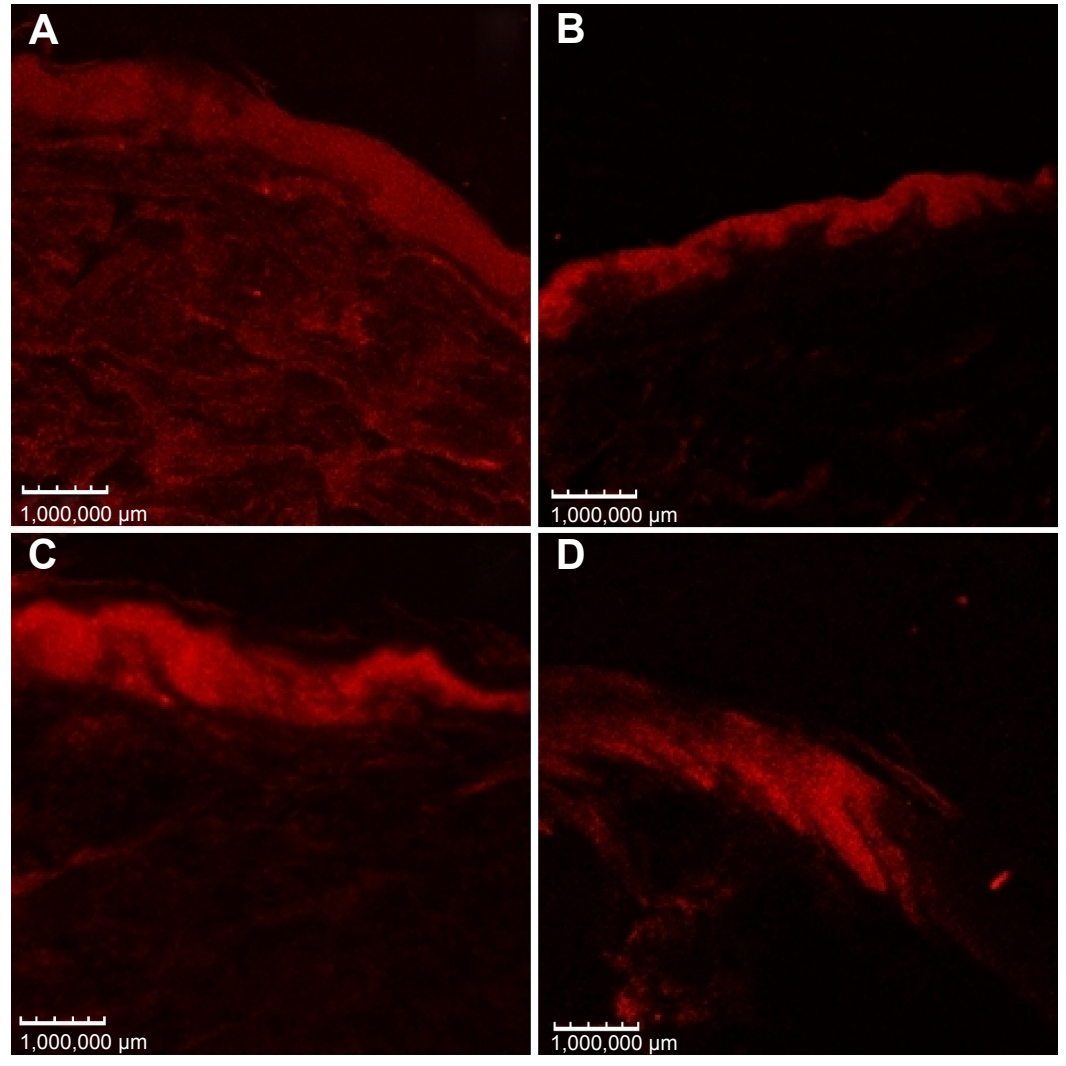

Figure 7 Confocal micrograph images of porcine ear skin after 8 hours treatment with (A) LP20, (B) LP80, (C) SP80, and (D) SP20 with Nile red fluorescent dye. Fluorescence images recorded with $559 \mathrm{~nm}$ excitation and $636 \mathrm{~nm}$ emission wavelengths.

Abbreviations: LP20, soybean lecithin and polysorbate 20; LP80, soybean lecithin and polysorbate 80 ; SP20, sorbitan monooleate and polysorbate 20; SP80, sorbitan monooleate and polysorbate 80 . 
Table 4 THP-I $\mathrm{CC}_{50}$, Leishmania amazonensis (amastigote) IC ${ }_{50}$, and selectivity index values of free SC, nanoemulsion, and amphotericin B 24 hours after preparation of the formulations

\begin{tabular}{lllllll}
\hline & SC & LP20 & LP80 & SP80 & SP20 & ANFB \\
\hline $\mathrm{CC}_{50}$ & $44.47 \pm 6.60$ & $8.95 \pm 6.62$ & $\mathrm{ND}$ & $17.53 \pm 6.19$ & $\mathrm{ND}$ & $>10$ \\
$\mathrm{IC} \mathrm{F}_{50}$ & $0.42 \pm 0.13$ & $0.32 \pm 0.05$ & $0.94 \pm 0.17$ & $0.26 \pm 0.06$ & $0.53 \pm 0.1$ & $0.07 \pm 0.06$ \\
$\mathrm{SI}$ & 105.88 & 27.97 & $\mathrm{ND}$ & 67.42 & $\mathrm{ND}$ & $>142$ \\
\hline
\end{tabular}

Note: $\mathrm{CC}_{50}$ and $\mathrm{IC}_{50}\left(\mu \mathrm{g} \cdot \mathrm{mL}^{-1}\right)$ are expressed as mean \pm standard deviation $(\mathrm{n}=3)$.

Abbreviations: $\mathrm{CC}_{50}, 50 \%$ cytotoxic concentration; $\mathrm{IC}_{50}$, half maximal inhibitory concentration; ANFB, amphotericin B; LP20, soybean lecithin and polysorbate 20; LP80, soybean lecithin and polysorbate 80; ND, not determined; SC, (E)-3-(3-nitrophenyl)-I-(3,4,5-trimethoxyphenyl) prop-2-en-I-one; SI, selectivity index (CC $\left.{ }_{50} / C_{50}\right)$; SP20, sorbitan monooleate and polysorbate 20; SP80, sorbitan monooleate and polysorbate 80.

\section{Conclusion}

SC was successfully incorporated in nanoemulsions using a spontaneous emulsification method. The different combinations of lipophilic and hydrophilic surfactant did not influence SC content and the association efficiency of nanoemulsions. All nanoemulsions presented nanometric sizes, negative zeta potential values, low viscosity and $\mathrm{pH}$, and most were monodispersed. The factorial design showed that the presence of soybean lecithin had a significant effect on droplet size, PDI, zeta potential, viscosity, $\mathrm{pH}$, and $\mathrm{SC}$ dermis retention. The interaction between lipophilic and hydrophilic emulsifier presented a significant effect $(P<0.05)$ on droplet size as well as on the epidermal and dermal penetration of SC. Altogether, based on the physicochemical properties and dermal retention results, LP20 was the most promising nanoemulsion. Our results have shown that LP20 nanoemulsion presented a high activity against intracellular amastigotes of L. amazonensis in THP-1 cells. Furthermore, when the parasitic inhibition profile is considered, LP20 presented both stability and maintenance of leishmanicidal activity.

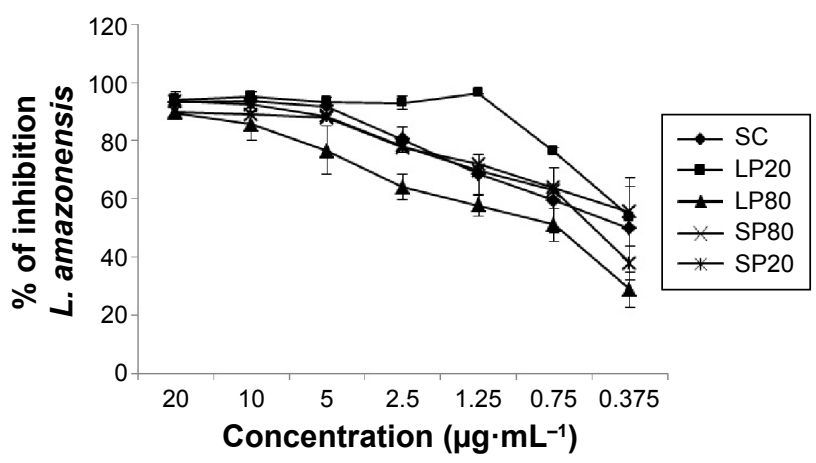

Figure 8 Inhibitory effects of nanoemulsions on Leishmania amazonensis in vitro tested 24 hours after the preparation of formulations.

Notes: Adherent THP-I cells were infected at a ratio of I:I0 cell/parasite $L$. amazonensis and treated for 48 hours with free SC and SC loaded into nanoemulsions in a concentration range of $0.375-20 \mu \mathrm{g} \cdot \mathrm{mL}^{-1}$. Results are expressed as the mean \pm SD of the percent inhibition of parasite growth $(n=3)$.

Abbreviations: LP20, soybean lecithin and polysorbate 20; LP80, soybean lecithin and polysorbate 80; SC, (E)-3-(3-nitrophenyl)-I-(3,4,5-trimethoxyphenyl) prop-2en-I-one; SD, standard deviation; SP20, sorbitan monooleate and polysorbate 20; SP80, sorbitan monooleate and polysorbate 80 .

\section{Acknowledgments}

This work was supported by Coordenação de Aperfeiçoamento de Pessoal de Nível Superior (CAPES/MEC) (Network Nanobiotec - grant 902/2009 and PROCAD - grant 552457/2011-6) and CNPq (grant 453927/2014-9). The authors also thank these agencies for their research fellowships.

\section{Disclosure}

The authors report no conflicts of interest in this work.

\section{References}

1. Myler PJ, Fasel N. Leishmania After the Genome. Seattle: Caister Academic Press; 2008.

2. World Health Organization. Control of Leishmaniases. Report. Geneva: World Health Organization; 2010:WHO Technical Report Series, 949.

3. Kim DH, Chung HJ, Bleys J, Ghohestani RF. Is paromomycin an effective and safe treatment against cutaneous leishmaniasis? A metaanalysis of 14 randomized controlled trials. PLoS Negl Trop Dis. 2009;3(2):e381.

4. Ben Salah A, Zakraoui H, Zaatour A, et al. A randomized, placebocontrolled trial in Tunisia treating cutaneous leishmaniasis with paromomycin ointment. Am J Trop Med Hyg. 1995;53(2):162-166.

5. Ben Salah A, Ben Messaoud N, Guedri E, et al. Topical paromomycin with or without gentamicin for cutaneous leishmaniasis. NEngl J Med. 2013;368(6):524-532.

6. Larbi EB, Alkhawajah A, Algindan Y, Jain S, Abahusain A, Alzayer A. A randomized, double-blind, clinical-trial of topical clotrimazole versus miconazole for treatment of cutaneous leishmaniasis in the Eastern Province of Saudi-Arabia. Am J Trop Med Hyg. 1995;52(2):166-168.

7. Singh S, Sivakumar R. Challenges and new discoveries in the treatment of leishmaniasis. J Infect Chemother. 2004;10(6):307-315.

8. Storer E, Wayte J. Cutaneous leishmaniasis in Afghani refugees. Australas J Dermatol. 2005;46(2):80-83.

9. Seeberger J, Daoud S, Pammer J. Transient effect of topical treatment of cutaneous leishmaniasis with imiquimod. Int J Dermatol. 2003;42(7): 576-579.

10. Sampaio RNR, Lucas IC, Takami HL. Inefficacy of the association $\mathrm{N}$-methyl glucamine and topical miltefosine in the treatment of experimental cutaneous leishmaniasis by Leishmania (Leishmania) amazonensis. J Venom Anim Toxins Incl Trop Dis. 2007;13(3):598-606.

11. Monge-Maillo B, López-Vélez R. Therapeutic options for old world cutaneous leishmaniasis and new world cutaneous and mucocutaneous leishmaniasis. Drugs. 2013;73(17):1889-1920.

12. Boeck P, Falcão CAB, Leal PC, et al. Synthesis of chalcone analogues with increased antileishmanial activity. Bioorg Med Chem. 2006;14(5): $1538-1545$. 
13. Yunes R, Chiaradia LD, Leal PC, et al. Chalcones as new drug leads against leishmaniasis. In: Richards R, editor. Current Trends in Medicinal Chemistry. Trivandrum: Research Trends; 2006:47-56.

14. Nowakowska Z. A review of anti-infective and anti-inflammatory chalcones. Eur J Med Chem. 2007;42(2):125-137.

15. Andrighetti-Frohner CR, Oliveira KN, Silva DG, et al. Synthesis, biological evaluation and SAR of sulfonamide 4-methoxychalcone derivates with potential antileishmanial activity. Eur J Med Chem. 2009;44(2): 755-763.

16. Rossi-Bergmann B, Falcão CAB, Zanchetta B, Bentley MVLB, Santana MHA. Performance of elastic liposomes for topical treatment of cutaneous leishmaniasis. In: Beck R, Guterres S, Pohlmann A, editors. Nanocosmetics and Nanomedicines: New Approaches for Skin Care. Germany: Springer; 2011:181-196.

17. Tadros T, Izquierdo P, Esquena J, Solans C. Formation and stability of nano-emulsions. Adv Colloid Interface Sci. 2004;108-109: 303-318.

18. Khurana S, Jain PNK, Bedi MS. Nanoemulsion based gel for transdermal delivery of meloxicam: physico-chemical, mechanistic investigation. Life Sci. 2013;92(6-7):383-392.

19. Baroli B. Penetration of nanoparticles and nanomaterials in the skin: fiction or reality? J Pharm Sci. 2010;99(1):21-50.

20. Kelmann RG, Kuminek G, Teixeira HF, Koester LS. Carbamazepine parenteral nanoemulsions prepared by spontaneous emulsification process. Int J Pharm. 2007;342(1-2):231-239.

21. Tonini ML. Desenvolvimento de um Teste Colorimétrico Para Triagem da Atividade Leishmanicida de Compostos Utilizando Leishmania amazonensis Expressando a Enzima Beta-Galactosidase [dissertation] Florianópolis: University Federal of Santa Catarina; 2013.

22. Tsuchiya S, Yamabe M, Yamaguchi Y, Kobayashi Y, Konno T, Tada K Establishment and characterization of a human acute monocytic leukemia cell line (THP-1). Int J Cancer. 1980;26(2):171-176.

23. Fumarola L, Spinelli R, Brandonisio O. In vitro assays for evaluation of drug activity against Leishmania spp. Res Microbiol. 2004;155(4): 224-230.

24. van de Loosdrecht AA, Nennie E, Ossenkoppele GJ, Beelen RH, Langenhuijsen MM. Cell mediated cytotoxicity against V937 cells by human monocytes and macrophages in a modified colorimetric MTT assay. A methodological study. J Immunol Methods. 1991; 141(1):15-22.

25. Sieuwerts AM, Klijn JG, Peters HA, Foekens JA. The MTT tetrazolium salt assay scrutinized: how to use this assay reliably to measure metabolic activity of cell culture in vitro for the assessment of growth characteristics, $\mathrm{IC}_{50}$-values and cell survival. Eur JClin Chem Clin Biochem. 1995;33(11): 813-823.

26. Garcia I, Pouzet C, Brulas M, Bouza E, Botto JM, Domloge N. Evaluation of THP-1 cell line as an in vitro model for long-term safety assessment of molecules. Int J Cosmet Sci. 2013;35(6):568-574.

27. Benita, S. Submicron Emulsion in Drug Targeting and Delivery. Amsterdam: Harwood Academic Publishers; 1998.

28. Wang L, Tabor R, Eastoe J, Li X, Heenan RK, Dong J. Formation and stability of nanoemulsions with mixed ionic-nonionic surfactants. Phys Chem Chem Phys. 2009;11(42):9772-9778.

29. Fiume Z. Final report on the safety assessment of lecithin and hydrogenated lecithin. Int J Toxicol. 2001;20(Suppl 1):21-45.

30. Benita S, Levy MY. Submicron emulsions as colloidal drug carriers for intravenous administration: comprehensive physicochemical characterization. J Pharm Sci. 1993;82(11):1069-1079.

31. Saberi AH, Fang Y, Mcclements DJ. Fabrication of vitamin E-enriched nanoemulsions: factors affecting particle size using spontaneous emulsification. J Colloid Interface Sci. 2013;391:95-102.

32. Wang L, Dong J, Chen J, Eastoe J, Li X. Design and optimization of a new self-nanoemulsifying drug delivery system. J Colloid Interface Sci. 2009;330(2):443-448.

33. Baroli B, Ennas MG, Loffredo F, Isola M, Pinna R, López-Quintela MA. Penetration of metallic nanoparticles in human full-thickness skin. J Invest Dermatol. 2007;127(7):1701-1712.
34. Baboota S, Shakeel F, Ahuja A, Ali J, Shafiq S. Design development and evaluation of novel nanoemulsions formulations for transdermal potential of celecoxib. Acta Pharm. 2007;57(3):315-332.

35. Liu W, Sun D, Li C, Liu Q, Xu J. Formation and stability of paraffin oil-in-water nano-emulsions prepared by the emulsion inversion point method. J Colloid Interface Sci. 2006;303(2):557-563.

36. Fronza T, Campos A, Teixeira H. Nanoemulsões como sistemas de liberação para fármacos oftálmicos. Acta Farm Bonaerense. 2004;23(4): 558-556.

37. Jumma M, Muller BW. Physicochemical properties of chitosan-lipid emulsions and their stability of parenteral fat emulsions. Int J Pharm. 1998;163:81-89.

38. Silvander M, Hellstrom A, Warnheim T, Claesson P. Rheological properties of phospholipid-stabilized parenteral oil-in-water emulsions effects of electrolyte concentration and presence of heparin. Int J Pharm. 2003;252(1-2):123-132.

39. Pal R. A novel method to correlate emulsion viscosity data. Colloids Surf A Physicochem Eng Asp. 1998;137(1-3):275-286.

40. Sznitowska M, Janicki S, Baczek A. Studies on the effect of $\mathrm{pH}$ on the lipoidal route of penetration across stratum corneum. J Control Release. 2001;76(3):327-335.

41. Cazares-Delgadillo J, Naik A, KaliaYN, Quintanar-Guerrero D, Ganem-Quintanar A. Skin permeation enhancement by sucrose esters: a pH-dependent phenomenon. Int J Pharm. 2005;297(1-2) 204-212.

42. Hoeller S, Sperger A, Valenta C. Lecithin based nanoemulsions: a comparative study of the influence of non-ionic surfactants and the cationic phytosphingosine on physicochemical behaviour and skin permeation. Int J Pharm. 2009;370(1-2):181-186.

43. Kirjavainen M, Mönkkönen J, Saukkosaari M, Valjakka-Koskela R, Kiesvaara J, Urtti AJ. Phospholipids affect stratum corneum lipid bilayer fluidity and drug partitioning into the bilayers. J Control Release. 1999; 58(2):207-214.

44. Santos CM, Oliveira RB, Arantes VT, et al. Amphotericin B-loaded nanocarriers for topical treatment of cutaneous leishmaniasis: development, characterization, and in vitro skin permeation studies. $J$ Biomed Nanotechnol. 2012;8(2):322-329.

45. Lopez A, Llinares F, Cortell C, Herraez M. Comparative enhancer effects of $\operatorname{Span}^{\circledR} 20$ with Tween ${ }^{\circledR} 20$ and Azone ${ }^{\circledR}$ on the in vitro percutaneous penetration of compounds with different lipophilicities. Int $J$ Pharm. 2000;202(1-2):133-140.

46. Fang JY, Yu SY, Wu PC, Huang YB, Tsai YH. In vitro skin permeation of estradiol from various proniosome formulations. Int J Pharm. 2001;215(1-2):91-99.

47. Thong HY, Zhai H, Maibach HI. Percutaneous penetration enhancers: an overview. Skin Pharmacol Physiol. 2007;20(6):272-282.

48. Nokhodchi A, Shokri J, Dashbolaghi A, Hassan-Zadeh D, Ghafourian T, Barzegar-Jalali M. The enhancement effect of surfactants on the penetration of lorazepam through rat skin. Int J Pharm. 2003;250(2): 359-369.

49. Som I, Bhatia K, Yasir M. Status of surfactants as penetration enhancers in transdermal drug delivery. J Pharm Bioallied Sci. 2012;4(1): 2-9.

50. Akhtar N, Rehman MU, Khan HMS, Rasool F, Saeed T, Murtaza G. Penetration enhancing effect of polysorbate 20 and 80 on the in vitro percutaneous absorption of L-ascorbic acid. Trop J Pharm Res. 2011;10(3): 281-288.

51. Idrees MA, Rahman NU, Ahmad S, Ali MY, Ahmad I. Enhance transdermal delivery of flurbiprofen via microemulsions: effects of different types of surfactants and cosurfactants. Daru. 2011;19(6):433-439.

52. Teeranachaideekul V, Boonme P, Souto EB, Müller RH, Junyaprasert VB. Influence of oil content on physicochemical properties and skin distribution of Nile red-loaded NLC. J Control Release. 2008;128(2): $134-141$.

53. Grogl M, Hickman M, Ellis W, et al. Review: drug discovery algorithm for cutaneous leishmaniasis. Am J Trop Med Hyg. 2013;88(2): 216-221. 
54. Poorrajab F, Ardestani SK, Foroumadi A, et al. Selective leishmanicidal effect of 1,3,4-thiadiazole derivatives and possible mechanism of action against Leishmania species. Exp Parasitol. 2009;121(4):323-330.

55. Ramirez-Macias I, Maldonado CR, Marin C, et al. In vitro antileishmania evaluation of nickel complexes with a triazolopyrimidine derivative against Leishmania infantum and Leishmania braziliensis. J Inorg Biochem. 2012;112:1-9.

56. Rodrigues KAF, Amorim LV, Dias CN, Moraes DFC, Carneiro SMP, Carvalho FAA. Syzygium cumini (L.) Skeels essential oil and its major constituent $\alpha$-pinene exhibit anti-leishmania activity through immunomodulation in vitro. J Ethnopharmacol. 2015;160:32-40.

57. Tiwari A, Kumar S, Suryawanshi SN, Mittal M, Vishwakarma P, Gupta S. Chemotherapy of leishmaniasis part X: synthesis and bioevaluation of novel terpenyl heterocycles. Bioorg Med Chem Lett. 2013;23(1): $248-251$.
58. Dagnino AP, Barros FMC, Ccan-Ccapatinta GV, Prophiro JS, Von Poser GL, Romão PRT. Leishmanicidal activity of lipophilic extracts of some Hypericum species. Phytomedicine. 2015;22(1):71-76.

59. Schwartz J, Moreno E, Fernández C, et al. Topical treatment of L. major infected BALB/c mice with a novel diselenide chitosan hydrogel formulation. Eur J Pharm Sci. 2014;62:309-316.

60. Brotherton MC, Bourassa S, Légaré D, Poirier GG, Droit A, Ouellette M. Quantitative proteomic analysis of amphotericin B resistance in Leishmania infantum. Int J Parasitol Drugs Drug Resist. 2014;4: 126-132.

61. Kaur G, Rajput B. Comparative analysis of the omics technologies used to study antimonial, amphotericin B, and pentamidine resistance in Leishmania. J Parasitol Res. 2014;2014:726328. doi:10.1155/2014/726328.

\section{Publish your work in this journal}

The International Journal of Nanomedicine is an international, peerreviewed journal focusing on the application of nanotechnology in diagnostics, therapeutics, and drug delivery systems throughout the biomedical field. This journal is indexed on PubMed Central, MedLine, CAS, SciSearch ${ }^{\circledR}$, Current Contents ${ }^{\circledR} /$ Clinical Medicine,
Journal Citation Reports/Science Edition, EMBase, Scopus and the Elsevier Bibliographic databases. The manuscript management system is completely online and includes a very quick and fair peer-review system, which is all easy to use. Visit http://www.dovepress.com/ testimonials.php to read real quotes from published authors. 